\title{
Covid heterodoxy in three layers
}

\author{
Peter Godfrey-Smith ${ }^{1}$ (D)
}

Accepted: 5 October 2021 / Published online: 27 November 2021

(c) Crown 2021

\begin{abstract}
Lockdowns and related policies of behavioral and economic restriction introduced in response to the COVID-19 pandemic are criticized, drawing on three sets of ideas and arguments that are organized in accordance with the likely degree of controversy associated with their guiding assumptions. The first set of arguments makes use of cost-benefit reasoning within a broadly utilitarian framework, emphasizing uncertainty, the role of worst-case scenarios, and the need to consider at least the medium term as well as immediate effects. The second draws on assumptions about the political value of basic liberties. The third draws on ideas about the roles of different stages within human life.
\end{abstract}

Keywords COVID-19 · Lockdown · Trade-off · Liberty

\section{Introduction}

Since the start of the COVID-19 pandemic in the early part of 2020, I have often not supported, and have sometimes been startled by, the measures taken in response. ${ }^{1}$ That remains the case. Many developed countries have opted to impose severe restrictions on behavior and economic activity for significant periods of time. I oppose much of this. In the language that has become familiar, I am generally opposed to "lockdowns." This term refers to a family of policies that

\footnotetext{
${ }^{1}$ This essay was written and posted online in stages from late 2020 through mid 2021. The current version includes updates in the light of changing conditions. It's presently unclear whether this discussion will be applicable primarily to the next crisis of this kind we face-if the pandemic fades over the coming months-or remain relevant (unfortunately) to an ongoing problem. I would like to thank Rob Bezimienny for detailed and valuable discussions of these topics, and also thank Gigi Foster, Euzebiusz Jamrozik, Kim Sterelny, Charles Rathkopf, Jessie McCormack, Jacob Benson, Anya Plutynski, Jacob Stegenga, and several other correspondents. Two anonymous referees for the journal made helpful comments on the penultimate draft.
}

Peter Godfrey-Smith

pgodfreysmith@gmail.com

1 School of History and Philosophy of Science, University of Sydney, Carslaw Building, Sydney, NSW 2006, Australia 
differ significantly across contexts, and the diversity in and around this category will be discussed below, but the restrictions I have in mind include taking schools online, closing businesses, and imposing restrictions on ordinary movement and interaction.

My reasons for dissent form a series of "layers," in a sense, where what distinguishes them is how unorthodox I take the assumptions or premises used in the arguments to be. Some of my reasoning I see as not especially controversial in principle, while other parts make use of more contentious ideas. The ordering is not essential; you might accept some of the "more" controversial ideas while rejecting some of the "less."

The first layer looks at the cost and benefits of lockdowns in a framing where our aim is simply to do the most good with the least harm. Especially when we consider all ages, look at effects on inequality, and factor in the long term, there is a good chance that lockdowns will, in at least many cases, do more harm than good. It is hard to be sure-part of my focus will be the role of uncertainty itself, and how to think about worst-case scenarios of various kinds. But there are reasons to doubt, especially, that large-scale and extended lockdowns are beneficial overall.

The second layer looks at how some of the restrictions that have often been introduced in Western societies relate to basic liberties, and the roles of policing and coercion. Even if lockdowns were likely to do more good than harm by the criteria discussed in layer 1, lockdowns in many cases involve a suppression of liberty and autonomy that has its own importance, and is a basis for reconsideration.

The third layer makes use of ideas about the overall shape we might look for in our lives, the nature of valuable and meaningful experiences, the roles of aspiration and fear, and how the situations of younger and older people should be related in policy decisions. I see these factors not as providing an independent argument against lockdowns - as those in the second layer could, in principle-but as affecting the other arguments by bearing on the relative weighting of factors. In our present situation, some health risks might be reduced by shrinking the longer-term opportunities that younger people have, and also by reducing human contact, including contact with others when near the end of life. If you think that some activities have a special role in making life worth living, risk reduction in itself is not always something to promote when it suppresses these activities. In particular, we have a responsibility not to narrow and degrade the life paths open to the young.

My aim is to give reasons for rethinking, and mostly rejecting, lockdown-like policies, given their total network of downstream effects. What do I think the right policies in response to the pandemic would have been, and should be now? In general I think the right goal is to slow the spread of the virus and protect healthcare systems through a range of measures that are not too destructive in other ways-not destructive of livelihoods, education, basic liberties, and essential forms of human contact. My discussion is mostly concerned with developed-world democracies (though I'll look sometimes at a broader international context). Restrictions vary in stringency and duration, and in some circumstances brief resets might do some good. But as experience has shown over the past year, lockdowns become a trap. In general and especially from now on, I support no closed schools and much less restriction on 
economic activity and normal life. Young people are being made to pay too high a price.

The most organized policy initiative opposed to lockdowns is the Great Barrington Declaration, which advocates "focused protection" [1]. This would involve using significant resources to enable older people and those with health problems to be kept safe during outbreaks (for example, paying the salaries of older and more infirm workers who cannot work from home), while younger people lived more normally. I am in partial agreement with this approach. ${ }^{2}$ I've learned that indicating this agreement leads to the inference that I don't take Covid seriously as a problem, actively want to see people infected with the virus, and/or support a kind of extreme libertarianism. ${ }^{3}$ It's worth stating at the outset that those are not my beliefs. I take the problem of Covid entirely seriously and write from a political position on the center-left, especially on economic matters. One reason for writing this paper is concern over political polarization in this area, and an absence of constructive exchange and consideration of middle-ground positions.

\section{First layer: the balance of harms}

In this section I assume we have the goal of minimizing harm during and after the pandemic, working within fairly standard ideas about what harm is. Throughout this paper I work within what I take to be mainstream assumptions about mortality and other immediate harms Covid itself has brought about. Over 4.7 million deaths have been attributed to Covid worldwide, including over 670,000 in the US [2]. The majority of those who died have been older people, many with other health problems. In many (not all) countries, the reported median age of death from Covid has been around the same age as the life expectancy in that country-78 in the USA, 83 in England and Wales, 86 in Australia [3-5]. Especially given that fact, tracking "excess deaths" from all causes - the total number of deaths during some period (a week, a year), compared to some average or baseline applicable to that period (e.g., the average for a particular week over the last 5 years, or the average per year across 5 years) is often more appropriate, though it can be controversial given the effects of lockdowns and related policies themselves on mortality. The USA experienced over 522,000 excess deaths between March 2020 and the end of the year, around 23\% more than expected [6].

Covid's "infection fatality rate" (chance of death, if infected) depends greatly on age and may also differ across strains of the virus. Drawing on [7], a paper that compares many countries, the first age group for which the chance of death, if infected, is more than one in a thousand is around age 40-44. The first age group for which

\footnotetext{
${ }^{2}$ Looking back at the Declaration, the drafters perhaps seemed more concerned for low-risk people to live normally rather than, as I put it above, trying to slow the spread of the virus and protect healthcare systems through measures that are not too destructive in other ways. But the general principle of "focused protection," as opposed to indiscriminate restriction, is one I support.

3 From here I will abbreviate- “Covid," rather than "COVID-19" or "Covid-19."
} 
the chance is one in a hundred is 65-69. For school and college age people, the infection fatality rate is less than one in ten thousand. Once a person gets into their $80 \mathrm{~s}$, the rate is much higher, up around one in ten. So the infection fatality rate for a country depends on its distribution of ages. Accepted figures for western democracies range from around $0.25 \%$ to $1 \%{ }^{4}$ Covid also causes many harms short of mortality, including longer-term effects on some of those who survive ("long Covid"), which I discuss near the end of this section.

The argument of this paper is that although Covid is a serious problem, lockdowns (and some related restrictions - see below) are not in general an appropriate response. Short resets may be worthwhile in some circumstances, but lockdowns tend to become entrenched, continuing for months in many cases and repeated when infections increase. I will make the case that restrictions of this kind are a bad policy choice in at least many settings. With overwhelming attention focused on reducing Covid cases in a situation where young people are not at great risk, other sources of harm are neglected. Some of these harms are clear and concrete (disruption of education, bankruptcies) and others are harder than to measure, including the varied effects of inequality, and the consequences of raising children in an atmosphere of isolation and fear. The decisions in developed democracies that are my main focus also have effects on the developing world, where a health catastrophe stemming from stalled health programs and hunger is growing. In some ways, the international problem entirely dwarfs the local ones within developed countries, but I will mostly discuss "local" effects of lockdowns, accepting for present purposes that governments have a special responsibility to their own populations. The case is strengthened if the international side is included [8].

Making a general argument here may seem difficult because of the diversity of measures seen in different settings. Some think that "lockdown" is not a real enough policy category to be a target of critique at all. ${ }^{5}$ My response is to discuss the policies I am concerned with individually, not worrying exactly where "lockdowns" begin and end. And although the diversity is real, these policies are also unified in obvious ways. There are common motivations behind the fact that a great many American children have missed over a year of in-person public school and the fact that a woman in Australia was arrested in handcuffs for advocating a peaceful and masked protest, on Facebook. These events raise different questions, but they occurred as responses to the same problem and similar justifications were offered. Below I will treat the category of "lockdown" fairly loosely-in philosophical jargon, it might be seen as a "cluster concept"-and will set aside the term and discuss specific policies in many contexts.

\footnotetext{
4 These fatality figures do not cover the Delta variant. At present, it appears clear that the Delta variant is more infectious than the original strain, but unclear whether it causes more serious illness. These fatality figures also assume the person infected has not been vaccinated.

5 For criticism of the present paper (in an earlier version) that includes this view, see [9], I reply in [10]. Some organizations explicitly encourage avoidance of the term "lockdown" in messaging (e.g., the American Medical Association [11]). In contrast, the term has been used often in UK government publications, and that government has a website headed: "Coronavirus: A history of English lockdown laws" [12].
} 
A more challenging problem arises with the kind of argument I am trying to make. I say that an intense focus on immediate medical harms is sidelining consideration of more scattered, diverse, and longer-term harms arising from shuttered businesses, disrupted educations, alienation, and the like. But those harms will be harder to track and quantify, and often more inherently unpredictable as they involve long causal paths that wind through networks affected by other factors. How can one argue that we might be doing more harm than good through lockdowns if the harms I am emphasizing are so sensitive to other actions, and hard to predict and quantify? Should we concentrate on the shorter-term harms that we can have more control over? That would be a mistake. Uncertainty about longer term harms does not make them smaller or less important. We grapple with the threat of longer-term harms all the time in other areas. Environmental policy is an example, even if we have often not done especially well in that case. The difficulty of considering the medium and long term is no reason to base policy only on the short term.

Policy over the last year has been guided by epidemiologists and health officers-people with a professional focus on one kind of harm. They also pay particular attention, understandably, to pessimistic and worst-case scenarios ("reasonable worst case scenarios" had an important role in UK policy in 2020: [13]). They do not want to underestimate or under-predict harms of the particular kind they are concerned with. In some policy settings, a tendency to focus on particularly bad possible outcomes, even when they might be unlikely, can be prudent, and many economies can absorb some amount of over-preparation and over-caution. A background picture operates in which overdoing a response might be unfortunate, but not doing enough might be catastrophic.

In the circumstances we are in now, though, these habits of assessment become a problem, because of the sheer size of the costs on the other side-the harms done by lockdowns. ${ }^{6}$ While pessimistic scenarios on the health side are made very salient, pessimistic scenarios on the other side are rarely seen on the table. Those are, again, the effects of economic dislocation and unemployment, also the effects of disrupted education, with each of these having stark consequences for inequality. Here, as with Covid itself, both pessimistic and optimistic pictures of what might happen are available. I am not suggesting that lockdowns on the scale of a few weeks have significant worst-case scenarios, and that is where lockdowns tended to start. But once they are imposed on a scale of months, the situation is different. The consequences of this amount of economic dislocation and other disruption could include a wholesale breakdown of social order. The consequences of suddenly expanding the educational gap between wealthy and poor children, owing to the greater ability of rich families to keep their kids' education going through public school closures, will surely be bad, and might—again on a pessimistic scenario_-be catastrophic. But all

\footnotetext{
${ }^{6}$ So here I disagree with Lipsitch, who, in remarks on this issue [14], quotes Trichopoulos and Adami [15] with approval: "When the real or presumed risk involves communicable agents, such as the prions that cause bovine spongiform encephalopathy (mad cow disease), no precaution, however extreme, can be considered excessive." This attitude will often be reasonable, but not when the precautions in question have costs of their own that are hard to predict and may be massive, especially when extended for long periods.
} 
through 2020 and after, pessimistic concern about Covid and its health effects has continually been made salient while comparable concern about the effects of lockdowns has been sidelined. Policy has been justified through worst-case scenarios about the virus itself, and rather rosy ones on the other side: "people will adjust, and we will build back better."

It is simply an error to consider worst-case scenarios on one side and not the other. An uncharitable interpretation of the situation is that the scenarios that drove policy have been not worst-case scenarios overall, but worst-case scenarios that the people making decisions today might be blamed for. High death rates in 2020-2021 are in that category. Bad outcomes years in the future, filtered through other causes, are not. Unlike some lockdown critics, I think that most of the people making the decisions I disagree with are genuinely and with great effort trying to do good. But some of the local incentives that operate in situations like this do have the capacity to cause problems. And once again, a good part of this error might be explained by that tendency to start, in early 2020, with lockdown plans that apply over a few weeks, where the stakes are lower, and not rethinking-or finding it hard to escape -once the scale becomes different.

Perhaps as I am someone whose life was so much built out of good educational opportunities, this facet of the problem seems especially pressing to me. Data has flooded in about the differential effects of Covid-related school closures on rich and poor children, and also on children from different racial backgrounds [16]. The US is the acute case here, where a great many urban public schools provided only online learning for most of 2020 and continued for a good part of 2021. Private schools have in most cases been open, and even when wealthier kids are not in classrooms, their living circumstances are more conducive to getting some benefit from online classes. Schools have reported dropping test scores and widening gaps between racial groups. Some children seem to be have literally gone backwards in skills and knowledge, and the degree of alienation with the activity of education itself is also alarming. What will the effects of this be ten years on? The USA is permanently in a state of some tension because of the way inequality tracks racial lines. Education is probably the main, though imperfect, way to ease such inequalities; in a meritocratic society with a market economy, education is the road up. For a smart person from an under-resourced background, educational opportunities can be life-transforming. School closures on a scale of weeks can have surprisingly bad effects on a child's progress, though in that case one can certainly imagine a catch-up. But when a child of 13 from a disadvantaged background loses over a year of in-person schooling while luckier children of the same age forge ahead.... If "reasonable worst case scenarios" on this side were given real weight, we would never, or only very briefly, close schools for Covid.

What applies to education also applies to the socialization of young people in the years before school, unemployment and small business failure, mental health, and more.

So we can see a structural problem in much discussion around lockdown policies: we should not accommodate pessimistic options on one side and not others. The harmlessness of over-reaction in some health policy contexts does not apply when all of normal life is being brought to a halt and the lives of already disadvantaged 
people are turned upside-down. To say these things is, again, not to say that the pessimistic projections in this area are accurate. My claim is that we should not base action on worst-case thinking on one side and not the other.

With these broad points about uncertainty made, I move to questions about the efficacy of lockdowns and their more immediate costs. The knowledge we have on this topic is in continual flux as measures are introduced and abandoned in different contexts, as variant forms of the virus arise, and as information of different kinds is gathered. Confident projections made from many sides have been not just overtaken, but steamrolled, by events. As above, the view presented here is supposed to be conditioned by an acknowledgement of uncertainty. In some special situations, with low levels of infection at the time decisions are made and the possibility of tight control of borders, lockdowns can achieve their intended goal at least for a while. This is what we have seen so far in New Zealand, and what Australia approximated through to the middle of 2021. But in other settings-Argentina, France, Peru, the UK-strict lockdowns have not worked well. Especially once the virus has become widespread and contact-tracing cannot keep up with every case, they do not appear very effective. A detailed comparative study that looked at 160 countries and a wide range of factors (geographic, economic, policy...) found that stringency of restrictions and use of lockdowns "did not appear to be linked with death rate."7

Recent debates on social media have seen a tendency to say that lockdowns "worked" if they had some immediate effect on the spread of the virus, without considering whether this made a difference in the medium term and whether they did more good than harm [21]. Though it is certainly difficult to work out whether they did more good than harm in a particular case, talk of lockdowns "working" if they merely slowed transmission for a short time is a misleading lowering of the bar.

Sweden and Florida (USA) have become important test cases. Sweden applied a fairly "light touch" to Covid, with voluntary distancing and schools kept open for most ages. Businesses were free to operate with some restrictions on numbers. As a result, throughout 2020 Sweden was the constant focus of competing narratives and skewed reporting of many kinds. An early hope of observers opposed to lockdowns was that Sweden would cruise through the one and only Covid "wave" with slightly elevated death rates in the short term, but be much better set up for the longer term. An increased infection rate in the 2020-2021 winter showed that this hope was excessive. The total number of Covid deaths seen in Sweden to the end of the March 2021 was over 13,000. Sweden had around 7000 excess deaths in 2020, compared to the average of the previous five years, where this is around $7 \%$ of total mortality for the year (less if an age adjustment is made) [22]. That put Sweden around the middle of the distribution of excess death rates for European countries, better than France, Belgium, Spain, Italy, and the UK, worse than Germany and worse than other Nordic countries. Both those who hoped Sweden would emerge largely unscathed and those who predicted disaster have been wrong. Among US states, Florida relaxed

\footnotetext{
7 [17]; see also [18, 19]; this last study did find support for masks, but not lockdowns. The former paper, from which I quoted, covered the first eight months of 2020. See [20] for a detailed survey of lockdown studies.
} 
nearly all Covid restrictions in September 2020. Despite predictions of disaster, Florida found itself in the middle of the ranking of states by Covid mortality rates through to July 2021.

The middle part of 2021 saw developments in both these cases, tending in opposite directions. In August, Florida saw a surge that took it up to the top of hospitalization and mortality rates in the US. Those rates have since dropped sharply, but the overall picture in the case of Florida remains different from how it looked in the earlier part of 2021 (with the state currently around the 10th highest mortality rate overall, rather than around 26th) [23]. Sweden, in contrast, has recently seen very low numbers of cases and, especially, of deaths [24].

The net effects of lockdowns, considering both health and economic consequences, have been examined through modeling and comparative studies. These have produced very different results, some claiming enormous costs of lockdowns and some claiming that no net harm done at all. Uncertainty about the question is unsurprising given the difficulties of assessing relevant counterfactuals, but some of the outcomes can be seen as reflecting questionable ways of setting up a comparison. For example, Grafton et al. [25], looking at the Australian case, argued that more stringent social distancing rules are better for both health and the economy. For the mortality cost of Covid they valued each life lost at AUD \$4.9 million. This number is not arbitrary and is used in some policy settings, but it makes no allowance for age - the number is the same for a lost life at 5 and at 90 . Use of that number with no consideration of alternatives that consider age is a problem. A companion paper using a different model [26] does take age of death into account. A problem with this second paper, and many others, is that when a no-lockdown policy is modeled (as opposed to later or softer lockdowns, as in [25]), it is assumed that no significant voluntary behavior modification occurs as the virus spreads-people do not change their behavior as the threat increases around them. Allen [20] argues that a neglect of voluntary behavioral change has been a consistent flaw in lockdown modeling, and an important empirical phenomenon throughout. In the absence of strict lockdowns, when infection rates are high people voluntarily alter their behavior in a way that reduces transmission, and compliance with very strict lockdowns is also limited. Models that ignore these voluntary choices overstate the effect of lockdowns.

Miles et al. [27] analyzed the UK case in the middle of 2020. They aimed to work out whether the costs of lockdowns imposed to date made sense given how much the UK government usually spends on a treatment that will preserve a human life for a year. They were willing to assume that a typical Covid death reduced a life by five or ten years on average. They used $£ 30,000$ as a standard pre-Covid UK NHS measure of the maximum cost of a treatment that increases life expectancy by one (quality adjusted) year, and also considered a doubling of that number. Using a range of different values for other key numbers, they found it almost impossible (one scenario in eighty, with every number set at its most pro-lockdown value) for benefits of the lockdown to outweigh the costs.

Some defenders of lockdowns have cited broad cross-country positive associations between doing well with Covid death or case rates, and doing well economically-this is taken to show that there is no trade-off between the two goals. But the graphs that have been given are, in many cases, anchored at the "successful" end by 
countries like South Korea and Taiwan, which did not have lockdowns during the period covered in the analysis, and at the "unsuccessful" end by countries like Italy, Peru, and the UK, which had stringent lockdowns but large numbers of deaths and much economic disruption. (Examples are in the note. ${ }^{8}$ ) The existence of no-lockdown success stories for health and GDP in Asia, along with disasters on both fronts in some European and Latin American countries with lockdowns, is nothing like an argument for lockdowns.

Comparative studies of this kind tend to look at coarse-grained figures such as GDP. They do not usually consider inequality. This is turning out to be a massive issue. A feature of the pandemic across a fair few countries, including the developed English-speaking democracies I focus on here, is that we have not yet seen the kind of broad economic breakdown that was initially feared. The next few years, given the explosion of public debt and other burdens, may be another matter, but it's reasonable to concede that a degree of economic resilience has been seen. However, I take it to be uncontroversial at this stage that the pandemic and its handling have widened gaps between rich and poor. ${ }^{9}$ Instead of a general meltdown, what we've seen is an increased concentration of wealth in the hands of the richest people and biggest businesses [32]. Even setting aside the rich, the tale of lockdowns over much of the world has been one where some people (including me) have not missed a single paycheck, while others have been fired or forced to permanently close their businesses.

In general, and especially in the US, rich people live a good deal longer than poor people-the richest in the US live 10-15 years longer than the poorest [33]. This is apparently not primarily due to different levels of health care. Similar, though smaller, gaps are seen in the UK and France, which have good universal health care systems. Robert Sapolsky describes this in terms of the "the psychosocial impact of being poor," an impact most marked in situations where others are not poor-where a gap is present. Poverty is not just being unable to buy nice things, it is having a harder, unhealthier, shorter life.

I'll finish this section with some additional points before moving to a new set of considerations.

\footnotetext{
${ }^{8}$ See [28]: Italy and UK are in one corner, with the worst outcomes on both measures, and South Korea and Taiwan are in the other corner, with the best outcomes on both. See also [29]: "No sign of a healtheconomy trade-off, quite the opposite.... Contrary to the idea of a trade-off, we see that countries which suffered the most severe economic downturns-like Peru, Spain and the UK-are generally among the countries with the highest COVID-19 death rate.... And the reverse is also true: countries where the economic impact has been modest—like Taiwan, South Korea, and Lithuania—have also managed to keep the death rate low."

Taiwan has now had a lockdown, which began in May 2021, after the end of the reporting period for the discussions criticized above. South Korea is occasionally described as having had lockdowns, but even their "level 4" restrictions are much lighter than those seen in UK/France/Australia-style lockdowns. For example, at level 4 movies and concerts are not allowed after $10 \mathrm{pm}$. Restaurants and cafes have limited seating and only take-out after 10. Schools are remote. There is no stay-home order [30].

${ }^{9}$ See [31]: "A report by Swiss bank UBS found that billionaires increased their wealth by more than a quarter (27.5\%) at the height of the crisis from April to July, just as millions of people around the world lost their jobs or were struggling to get by on government schemes."
} 
First, a commonly made argument for lockdowns is that without them, the health and hospital system will become overwhelmed. We need to "flatten the curve," as people said back in 2020, to prevent this. The argument is certainly a reasonable one in principle, and might motivate temporary measures aimed at slowing transmission, in concert with efforts to augment the health system's capacity. But the argument is now used to justify any amount of restriction applied for very long periods of time. Pressure on a health system should be considered in the mix with other costs and benefits, and considered alongside the possibility of lighter and more voluntarist approaches which can be sustained for longer with less damage to the social fabric.

Second, in sifting through the models used in these debates, a theme that has been discussed both in recent philosophy of science and in parts of science is brought home again. In modeling of the kind that is relevant here, there is no getting away from massive simplification of the system being studied, and a lot of numbers are set with educated guesswork. This is inevitable, but the way to handle the situation is then to cover a wide range of possibilities and scenarios, and only believe results that are robust across many different ways of setting things up. An "all roads lead to Rome" outcome is what one wants-or at least, many relevant roads. If someone only works with one number, then if that number has not been empirically determined in a solid way, this is something to worry about. Idealizing away from the complexities of voluntary behavioral change, in order to keep models tractable, is a related problem.

Lastly, debates about mortality and lockdowns are often followed by an appeal to the threat of "long Covid," the longer-term health effects of the infection. This is presently another unknown, though some reports are worrying. Should we be pessimistic and cautious about long Covid? Well, then we should be pessimistic and cautious about schools and inequality and much else. And once the policy discussion is shifted to include effects other than death, one can't claim that ordinary cost-benefit reasoning is trumped by a special, more fundamental harm. Non-mortal effects of Covid are on the table with other non-mortal harms. Over the past year, we've unfortunately become accustomed to the idea that "concern" in the case of Covid motivates extraordinary, unprecedented, and highly destructive measures. Within that thinking, once we become concerned about long Covid, lockdowns are on the table.

Am I concerned about long Covid? Yes. But given what we know, it is not enough to force people to shut down their businesses and prevent children going to school.

\section{Second layer: liberties}

The arguments above were organized around a goal of harm minimization in a broadly utilitarian sense. In liberal democratic societies, that sort of cost-benefit calculation is usually filtered by other principles. For example, some measures, even if they might be generally beneficial in their effects, would mistreat a minority or impinge on basic rights, and that usually rules them out. The measures might violate explicit principles in documents like the US Bill of Rights, or rights protected more by judicial interpretation and political tradition. This relates to the questions of 
what sorts of powers the police should have, and how the policing of minor matters should be handled. In societies like ours, there's one set of questions about how you would like people to behave, and another set of questions about which kinds of coercion and incentivization are acceptable.

During the pandemic, constraints of this kind have been loosened or lost, to varying degrees, in some societies where they had previously been important. The result has been the suppression of some basic liberties. Some of these relate to everyday, non-political behaviors-moving around, gathering, visiting people. Those shade into political activity-association for political reasons, protest, public speech. Questions of liberty also arise on the economic side-whether you are free to continue earning a living, through activity that would not attract attention or sanction in ordinary times.

Discussion of this side of the problem is made complicated by the very different ways these behaviors have actually been constrained over the past year in different places. When "orders" amount to strong advice without coercion, there's not much of an issue. In other contexts, behaviors that would have been routine attract significant fines. In still other contexts, formerly ordinary behaviors trigger forcible arrests, and enforcement policies breaking dramatically from prior expectations of what the police should do.

These differences between societies were made vivid by email correspondence after I posted online an early version of this paper. From the point of view of life in the USA, it may be hard to accept the idea of significant fines (and arrest if one persists) for trivial behaviors like going for a walk or sitting on a bench to eat takeaway food. The "liberties" debates related to Covid in the USA have been mostly concerned with mask mandates and business closures (and now also with vaccine mandates, which I don't consider here). The arguments of this section are less relevant to the US, both because the rules have been less intrusive, and because the police appear reluctant to interfere in everyday behaviors in a ways now common in countries like the UK, Canada, and Australia. Mask mandates, whether sensible or not, have limited effects on questions of liberty, at least in comparison with what has happened elsewhere. And while business closures do raise questions of liberty, especially in societies without much of a safety net, in most of this section I will set the economic aspect to one side. I'll be concerned with more everyday behaviors, and some kinds of political expression. Especially in urban areas where most people who are not rich have small living quarters, just being about to spend time outdoors is an important liberty. So is visiting and getting to know people. These are related to behaviors with a political dimension, but a lot of the time they don't attract much ethical or legal interest because they are so basic to human life.

Where everyday behaviors are constrained, heavy-handedness leads to protest, and hence further suppression of behaviors that it would normally be unthinkable to penalize. In Australia, as noted above, a woman was arrested for a Facebook post that encouraged people to attend an anti-lockdown protest-a protest explicitly 
described as including social distancing. She was arrested while pregnant, at home, and placed in handcuffs. ${ }^{10}$

During the winter 2020-2021 UK lockdown, people were not allowed to be outside the home except for a narrow range of reasons-essential shopping, exercise, helping those in immediate need, and some others. A fine could be issued for mingling with more than one person from a different household outside of an established "support bubble." Twelve men were fined for playing dominos together in a closed restaurant. Fines in England during the most recent lockdown started at $£ 200$, and 32,000 fines were given out in England and Wales between March and the end of 2020 [35].

Once lockdowns extend for many weeks or months, the refusal to allow ordinary human circulation and contact is a major imposition. Occasionally the UK fines have been issued in a ridiculous way. Two women who drove 5 miles, parked apart, and went for a walk together were fined. "Derbyshire Police said that driving to a location to exercise 'is clearly not in the spirit of the national effort to reduce our travel, reduce the possible spread of the disease and reduce the number of deaths" "[36]. The police backed off this case after media attention.

In Australia, when lockdowns are in force the fines are heavier-often over $\$ 1000$ AUD and more recently, with compliance fading, around $\$ 5000$ - for offences like washing one's car, eating takeaway food outside, or visiting friends. In Victoria, the most urbanized and politically progressive state, these fines have been given out in tens of thousands [37]. This has been coupled with a wildly irresponsible use of existing laws, as seen in the woman arrested at home for the Facebook post, who was charged with "incitement."

The past year has also seen some excesses that are not representative, but indicate what can happen. In Melbourne (Australia), 3,000 people in public housing towers were put without warning into the hardest of hard lockdowns, surrounded by police and not being allowed to go outside of those high-rise buildings at all for 14 days, with food brought in by authorities, because of a Covid cluster in that (largely immigrant) community. Despite the state government being completely unrepentantPremier Daniel Andrews: "We took the steps that the experts said were necessary to save lives"- this case looks likely to make its way into history as one of the worst Covid-related abuses of power in Western democracies [38].

What sort of role should these arguments about basic liberties play? There are a couple of ways they might enter into policy. From the viewpoint of a pure or "absolute" form of libertarianism, many lockdown measures could never, in principle, be justified. I don't agree with a view of that kind. Those "absolute" forms of libertarianism tend to make a philosophical error. They mistake valuable political constructs—rights and liberties - for entities somehow given by Nature itself. The right to move around, to express opinions, or to visit family and friends is not something

\footnotetext{
${ }^{10}$ See [34]. The Facebook post for which Zoe Buhler was arrested said: "PEACEFUL PROTEST! All social distancing measures are to be followed... Please wear a mask....".

"State Premier Daniel Andrews defended the arrest, saying protests undermined public health efforts.... 'Now is not the time to protest about anything. Because to do so is not safe."'.
} 
bestowed by the universe or by laws of human reason. These are, instead, normally and reasonably protected facets of everyday life in societies like ours.

While not absolute, these freedoms have a special status because they are foundational to the way we live, and underly other activities like political participation and caring for others. Though some of these freedoms enjoy indirect legal protection through their political manifestations or through ordinary criminal law, they are in many cases so basic and ordinary that they don't seem to be subject to a lot of legislation, and the case I am making on their behalf is not a legal one. My case is based on what I take to be central norms and principles of liberal democratic societies.

Arguments expressed in terms of liberty are unpopular in center-left circles as they are associated with economic libertarianism, opposition to environmental regulation, opposition to measures prohibiting discriminatory business practices, and so on. I don't defend libertarian arguments of those kinds; none of that is on the table. With "absolute" versions of libertarianism set aside, what is the relationship between the arguments of this section and those of the previous? In the previous section, I looked at a weighing of harms of the following kind. On one side, I assume that reduced interaction between people leads to some reduction in the transmission of the virus. On the other side are lost jobs, disrupted schooling, bankrupt small businesses, and the distinctive ills of increased inequality. Now we add a set of costs that are not economic in character, and instead involve a suppression of behaviors that have an integral role in the everyday texture of life in liberal societies, and in some cases, political expression. These costs (as with the first layer) include dangers relating to the longer term, such as the entrenching of coercive habits in local authorities that are likely to lead to ongoing harm even after the pandemic is over. Powers gained tend not to be willingly relinquished.

If the argument, again, comes down to questions of balance, then other forms of behavioral constraint are worth discussing. What about overnight curfews, which have occasionally been imposed outside of the pandemic? Many might be questionable because of their role in the over-policing of marginalized groups, but they do not much affect the liberties I am concerned with here, because what is prohibited at night is permitted in the daytime. What about the famous blackout of UK urban areas, such as London, during the WW2 "blitz"? This was an attempt to eliminate all light from cities at night to impede German bombers. The measures were enforced, and some people thought the rules went too far (though I think this opinion was not common). Collateral harms included increased numbers of accidents and sexual assaults. But as with curfews, blackouts were not an absolute suppression of movement, or even a significant constraint on behaviors of the kinds I am talking about. They are more akin to mask mandates than lockdown rules.

I accept that in some circumstances some of these liberties can be compromised to a degree, as part of a larger balancing. ${ }^{11}$ As with the disruption of schooling, the duration of the suspension matters. Measures that have limited importance when

\footnotetext{
11 See [39] for detailed discussion of different kinds of liberty at issue in this situation, and an argument that some of these liberties should only be suppressed on far stronger grounds than have been available in this case.
} 
they apply over a two-week period are a different matter when extended for months, and when they are reintroduced repeatedly. Within this context of balancing, longerterm effects are again important. It is bad to have a situation where the police are routinely spending a lot of their time harassing people for trivial things-gathering, meeting friends at home, going on walks together, and so on. We don't want a lot of police action directed at those non-crimes. This should be extremely rare, but it is now becoming common, and is changing the relationships between populations and their police forces.

It is important to remember how these policies got onto the table. In a December 2020 interview, Neil Ferguson, an Imperial College epidemiologist who has been influential in UK government decisions, looked back over discussions in early 2020 as the pandemic spread [40]. The idea that lockdown was a genuine possibility in a modern European context initially seemed outlandish. Then the Chinese showed lockdowns could apparently be effective, and the Italians followed: "It's a communist one party state, we said. We couldn't get away with it in Europe, we thought.... And then Italy did it. And we realised we could." Similar comments were made by an Australian counterpart around the same time- "Maybe we wouldn't have even thought of it had Wuhan not done it" [41]. In those early months, public discussion showed a degree of reluctance to go down this road. But the policy quickly took off. I suspect that all sides - those in favor and those against-were surprised at the willingness of people to acquiesce in these measures. Even in the case of the extreme Australian lockdown discussed above, a majority of people affected did support it, according to surveys at the time. In that particular lockdown, the cordoning of the main urban area was routinely described as the "ring of steel". The ring of steel? It sounds like something from a dystopian novel or fascist scenario.

In this section I've not much discussed the economic side, but we should think about this aspect of the situation briefly, especially given the desperation of people watching their previously uncontroversial way of making a living being suppressed for months and in many cases wrecked altogether. As noted above, I don't support a generally libertarian view of economic matters, but the societal context makes a difference. It is possible to arrange a society with sufficiently generous safety nets that it makes sense to see the operation of most small businesses as, in a sense, optional. We can ask the proprietor of a normally uncontroversial business to close, for some broader societal benefit, and know they'll be fine. Some societies are an approximation to this, but only a few. It is not "economic libertarianism" to think that forcing someone to shut down in a situation with totally inadequate safety nets is more than an ordinary financial harm. The economic context in which they operate is one in which their freedom to continue trading is integral to getting by (not being evicted from their home, and so on). In response to this, a person might say: "We just need proper safety nets!" That is fine; to take that path is to turn a society from one kind into the other kind. It's a huge change, and until it actually happens, it's not much of a response to the person whose business is shuttered.

A moment ago I noted that the people subject to the very harsh winter lockdown in Victoria, Australia, expressed support for the restrictions in various surveys. Support for lockdowns in the UK also seems to have generally been high [42]. I concede that this poses a challenge to a position like mine. I am making a plea for the 
preservation of liberties as we act to reduce the severity of the pandemic. But what if people do not care very much about these liberties? My response is to try to persuade them to care, remind them that they used to care, and highlight the long-term consequences of not caring.

\section{Third layer: aspiration, meaning, and fear}

One of the more controversial parts of the anti-lockdown literature on social media is the idea that we should not let our lives be run by fear, and this is what has happened, with the continual encouragement of many governments and much of the media. This, some think, is a mistake. ${ }^{12}$

That is not a cost-benefit argument, or one based on political/moral principle, but a point about our about overall emotional orientation to the situation. A reply is that when something causes great harm, you should be scared. I agree with the critique, though. A consistent problem in this area that has been the media-fed dominance of fear. It affects how children are encouraged to look at the world, and affects all sorts of reasoning that bear on the issues in earlier sections of this essay-whether lockdowns do net harm and whether the compromising of liberties is reasonable.

Another controversial theme, sometimes a trap for those speaking against lockdowns, is criticism of the extent of measures being taken to prolong the lives of people who are mostly already quite old. ${ }^{13}$ The median age of Covid-related death in developed countries tends to be around 80, similar to the life expectancy, while most of the costs of lockdowns fall on younger people. In reply, a person at or above their society's life expectancy does tend to have, on average, quite a few years to live. The "expectancy" is not a time-limit. And the idea that some lives are "worth more" than others is surely a moral wrong turn.

Yet another related issue, less frequently discussed but occasionally made stark by cases, is specific to the situation of older people. In the view of many, it is a disaster to die alone, and also to face alone, over many months, what feels likely to be the last part of one's life, or a large part of the last stages. For many old and infirm people, companionship and contact with loved ones are fundamental, and much of what it's worth being alive for. Some extra risks are worth taking if it means you can stay in contact with people who make your life meaningful. But this choice has been taken out of many people's hands. The decision to not allow visitors in aged care homes and many hospital settings has surely been the source of a great amount of unseen despair and misery over the course of the pandemic.

In some ways these three issues are very different-the role of fear, the role of age, the importance of human contact near the end. But they have some things in common. Concern about each of them might be associated with a sense that human life has a shape, a path relating earlier and later stages, and a sense that some

\footnotetext{
12 Examples on twitter include Dr Kulvinder Kaur (@ dockaurG) and A.J. Kay (@ AJKayWriter).

13 See [43] for a sophisticated critic of lockdowns getting into difficulties on this point.
} 
experiences have a special role in making life at particular stages valuable-for many people, at least—and the idea that physical safety isn't everything that matters.

This section of the essay will be about considerations of that kind, and how they affect the reasoning in earlier sections. This is an area where arguments play less of a role than they did in earlier sections. A discussion in his area is mostly, though not entirely, a matter of highlighting some things, making them vivid, and asking explicitly about considerations that are often handled in a more implicit way.

In the "first layer" of argument I made much of education at the K-12 level. Disadvantage at this stage can become entrenched and has huge effects downstream. This is perhaps the issue I am concerned about more than any other, but some lessdiscussed later stages in life have related forms of importance. Consider the situation of people who have left school, and are in their late teens and 20s. This is a stage of life, in developed democratic societies, that has a distinctive role of its own. Two projects at this stage are especially pivotal. One is finding the beginning of a path into economic life-choosing a career, or exploring a cluster of them through further education. The other is finding the beginning of a path into the tangle that involves close partnerships, sexuality, family, and domestic life-working out where one might fit into that side of things. Even outside of lockdowns, more of this is done online than used to be, but in the end one must meet people, interact, and spend time, in order to try out possibilities in this area.

These two activities-finding one's path in economic life and working out where one might fit in the world of romantic and domestic partnership-have been denied for long periods to many young people, on the basis of something that poses very little risk to them. These losses are a consequence of the closing of businesses and public spaces, the suspension of in-person teaching at universities and colleges, and a host of other measures that drastically reduce ordinary interaction and narrow economic activity. Imagine the situation of an 18 year old person whose aspirations lie in the area of competitive sports or the performing arts. Those are extreme cases, and many other pathways are affected to various degrees. These early-adulthood losses are more likely to be successfully made up than the disruption of school-age education, but this is still a problem, one generating a mental health burden, and one likely to lead to a loss of direction that many people will encounter downstream. In the area of schooling and also in this area, one of the chief responsibilities of older people who have established their place and now have power is maintaining open pathways for the young, not constraining and degrading their opportunities.

Covid is not the only context where this matters. "Intergenerational theft" is a problem of its own on the economic and environmental side, a problem now recognized by some influential people (such as Elizabeth Warren in the USA), but one allowed to wander on and cause all manner of injustices. An unwillingness to give some degree of priority to younger people and their prospects during the pandemic is another aspect of the same problem.

When talking about the "shape" of a human life, I am not saying that there are particular things that everyone should do-a path everyone should take, roles that everyone should try to have-and that we should push people down particular avenues. The point has more to do with choice and self-determination. Some central life choices are made-in an ongoing, revisable, often meandering way-in early 
adulthood. What young people do with their opportunities should be up to them. Some might choose not to do very much, at least at first, or not much that looks obvious from the outside. But they should have the choice, and these choices should be protected by older people who have made their own choices and have ended up with power and resources now.

The gravity of this factor depends a lot on the duration of restrictions placed on the relevant behaviors. As in the case of several issues discussed above, if largescale disruption goes on for a few weeks or a month, that is not a huge problem. And that is where lockdown policies began. But once it extends for a year, or more than a year, it becomes a bigger issue. Given the fact that this problem is the least acute over short time-scales, I worry that it will be the last to be remedied. It will be unsurprising if many young people lose something like two years with respect to the kinds of interactions and development being described here. The Guardian published in June 2021 the results of an informal survey of young Europeans reflecting on what happened to their lives over the last year [44]: "“Our whole generation has just been pushed aside as a problem to deal with later,' a 17-year-old in the north of England responded. From Germany, a 21-year-old wrote: 'We are the lowest priority.' And in France, a 21-year-old said he counted himself part of 'a sacrificed generation." I see these responses as entirely reasonable.

Some other quotes come into my mind repeatedly when writing about this topic. One is from the respected Australian journalist Peter Hartcher. The pandemic has been a challenge where, he says, "[t]he whole of the people had to accept some personal inconvenience for the common good. In successful countries they did; in failed ones they did not" [45]. This was a truly callous thing to say (as well as inaccurate, given the struggles of places like France). If you have already made your way through those formative years into middle age, your salary is coming in uninterrupted, and you are at home eating gourmet take-out delivered by others, then yes, lockdown might be described as a personal inconvenience. But if your business is wrecked, or you are 18 and trying to work out what sort of future you might pursue, it is a lot more than that.

In making this point about stages in life, I don't want to overstate things in a way that makes life paths look less flexible than they are. A person can wake up at age 70 and decide to do something totally new, and then do that thing for 20 years. But does anyone seriously doubt the differences between the roles of life stages described here? I don't think anyone doubts them; the question is whether we should factor them in. I think these considerations should be on the table, and like intergenerational theft, they are easy to lose sight of.

I don't claim that only lockdowns and related restrictions have these effects on young people's lives; the pandemic itself has an effect. In the absence of restrictions, the activities I emphasize above would still be affected. In the earlier section of this essay on costs and benefits, I noted that one reason the benefits of lockdowns can be overestimated in models derives from the way that models idealize away from voluntary behavioral change. As conditions get more worrying, people change their patterns of interaction. However, this does not show that in the absence of lockowns, voluntary behavioral change would have the same effects on young people's activities that lockdowns induce. The differences between normal life and conditions 
experienced under, for example, a UK-Australia-France style lockdown are enormous, with universities online, most visits to friends banned, and even outdoor activity massively restricted. It's reasonable to expect that through voluntary choice the behavioral patterns of young people would have been different from normal over the past eighteen months, but also very different from what has been imposed on them.

My argument for some prioritization of the young is related to the vexed issue of whether younger people's lives might be "more valuable" than older ones. Many versions of the question "Do some lives have more value than others?" are incoherent, but there is a meaningful question about an ideal, or a political commitment, that is gestured towards here. I endorse a commitment to the view that all lives should be accorded the same value in our society, but a "life" is a thing that extends, that has a shape, including earlier and later stages. To say that all lives have, or should have, the same value is not to say that the same efforts and investment should be applied at every stage of every life. It is instead to say that all those lives, each of which has its shape, should be counted equally in our attempts to handle opportunities, freedoms, costs, risks, and so on. Concern over intergenerational theft in economic and in environmental matters, again, is an application of this sort of reasoning. Intergenerational theft prevents the adult years of presently young people from having desirable features that earlier generations of adults enjoyed. In the realm of health policy, if someone asks how much we should spend to "save a life," the fact that "saving a life" is a misdescription of what we are trying to do also becomes salient. We all die eventually. No lives can be saved as wholes (except in the irrelevant sense in which some actions can prevent or facilitate a life coming into being at all). Those health policy question are better asked about extending lives, preserving lives. Though we can't save lives, we can save life-years. And once we are thinking that way, the age of people affected by the policies on the table does matter.

I'll next look at the role of fear itself in affecting attitudes to Covid over the last year.

Fear is an emotional response and disease is frightening. I don't criticize those who are frightened by Covid, even if they have picked up an exaggerated estimation of their risk [46]. Instead, my topic is the fueling of fear by media and governments, their trying to induce a level of anxiety that goes beyond what has "come naturally" to many people.

A lot of people worked out, around the middle of 2020, how afraid of Covid they are, and in many cases they ended up not as afraid as local authorities would like. This is part of what has motivated the coercive measures discussed in the previous section. Engaging in outdoor snowball fights does not seem very dangerous to some people in the UK, so it becomes necessary to fine the students who instigated a snowball fight $£ 10,000$ each [47]. It has also led to exaggeration and continual encouragement of fear by the mainstream media. ${ }^{14}$ This has its own consequences for stress and wellbeing, especially as children internalize the fear-drenched atmosphere around them, and I expect it to also lead to a degrading of trust in mainstream information sources.

\footnotetext{
${ }^{14}$ Here is the NSW (Australia) Chief Health Officer, Dr Kerry Chant: "We need to remember we're continually under threat and we are never going to go back to normal" [48].
} 
The New York Times, probably the most important print media organization in the world, furnishes examples. For over a year, the following text introduced a New York Times section called "At Home": "We may be venturing outside, tentatively or with purpose, but with the virus still raging we're still safest inside" (emphasis added). That text was finally taken down in May 2021 [49]. The Times has also spent a good deal of space on how to best present information about the vaccines. 'So what message should people hear? 'It's going to save your life-that's where the emphasis has to be right now,' Dr. Peter Hotez of the Baylor College of Medicine told The Times" [50]. That is the view of Dr. Hotez, an individual, but the Times has now approvingly quoted this message twice, months apart [51]. A lot of people know that if you are under 60 or so and healthy, the vaccine is probably not going to "save your life" because you are not at much risk in the first place. The vaccines are an amazing medical achievement and they are currently doing a great deal of good, but this reporting is apparently a case of deliberate tolerance of exaggeration to push home a desired effect.

These problems with fear-based messaging are not inherently tied to issues about the "shape" of human lives, though I do see a link in the unrelenting focus on risk.

Here is a summary of the main themes of this section. In societies of the kind discussed here, a person's later teens and 20s are very often the years when they begin to shape their aspirations. That is a project, and ideally a joy, of those years. When we are much older, something that is especially valuable is maintaining contact with the people who have been important parts of the journey that started decades before. One of the problems with Covid policies in many societies is that both of these activities have been thwarted, now for long periods, through curtailing opportunity for young and preventing people in aged care from staying in touch with those who matter to them. The nominal reason for this has been avoiding risk and preserving lives, and those are worthwhile goals, but they are not everything.

These considerations are not intended to provide a free-standing argument, but to condition the arguments discussed earlier. When considering costs and benefits of lockdowns (layer 1), the narrowing of aspiration is a real harm. This is a complement to the starker issues about elementary and high school education; I aim to encourage a reweighting of factors, so that in the mix of considerations on the table, our responsibility not to narrow the lives of the young is given a role. Regarding layer 2, one of the liberties worth considering is the freedom to live in a somewhat riskier way than others might choose, especially near the end of life. The objection will be that one person's riskier behaviors creates risks for others, whether they like it or not. This is a problem, but not an insuperable one. Those who want to be very cautious should have provision made for them. Those who want to be less cautious should be given some leeway. This leeway may have slight residual effects on the cautious, but one preference does not override the other; there has to be a balancing. 
In the previous section I discussed the possibility of a rather "pure" libertiesbased argument against lockdowns, though I did not endorse it. Might there be a argument based purely on the third set of considerations as well? If so, it would probably not be one I'd endorse. Too much concern with the proper shape of a human life, without this being filtered through a greater concern with autonomy, is likely to lapse into a kind of authoritarian perfectionism (you must live like this!). I see this third set of factors instead as modulating our thinking about policy choices within a democratic context in which liberties and personal self-determination are taken seriously.

That is the end of layer 3. I'll close with briefer consideration of some themes not covered so far.

One is a question of expertise. Lockdown critics whose fields lie outside of epidemiology and medicine, like myself, have been criticized for not being willing to "follow the science" and "listen to the experts." In areas of the present critique where medical and epidemiological details are especially relevant, I am cautious. But if we were to criticize all those who express opinions outside of their areas of expertise, we should criticize any epidemiologist making prescriptions about policy in a way that depends on basic values, or on questions about the political effects of inequality, or the effects of disrupted education on children, and so on. The fields relevant to this issue include virology, epidemiology, public health, evolutionary biology, economics, political philosophy, and many others. Especially when policing and education are being transformed, this is a whole-society problem.

Some people may think that once we get beyond the narrowly biological and medical questions, "expertise" is not real, and questions about basic values, in particular, are merely a matter of personal opinion. I don't agree with that, but even if it was true, each person would then have an opinion that is relevant; this would not be an argument for letting questions be settled by the scientific expertise of epidemiologists plus their personal opinions about how important inequality is, how important everyday liberties are, and so on. The Covid problem, given its many facets, is best addressed through a many-voiced exchange between people with different perspectives and different kinds of expertise.

On the basis of a lot of years thinking and writing about biological matters, I do make some empirical assumptions. I assume that SARS-Cov-2 will continue to evolve, as other viruses do. Some variants are likely to evade current vaccines, both in relation to transmission (as is currently being seen) and illness. For this reason and others, eradication of the virus is probably not possible, and the goal of "zero Covid" is unrealistic. In parts of the developing world, Covid is not of primary importance, partly because these populations are younger, because other health problems are more pressing, and perhaps for poorly understood reasons involving the virus itself. In addition, SARS-Cov-2 has many potential animal reservoirs. A large range of mammals are known to have become infected-cats, dogs, minks, gorillas. Animals are likely to remain sites of ongoing evolution in the virus.

A theme mentioned at the outset is also worth revisiting: the politicization of debates about Covid policy. The anti-lockdown view is instinctively associated with the political right in many people's minds. I reject, again, any such association. It's an unfortunate fact that a concern with liberties has been increasingly sidelined over 
recent years within the mainstream left, and this pre-existing realignment interacts with lockdown debates. On the other hand, concern with economic inequality and the increasing dominance of a few huge businesses, a focus on public education, and concern with disastrous effects of current policies on the developing world are still squarely topics of center-left concern, and their neglect during the pandemic is more novel.

A factor related to this political dimension, but one with a more positive role, is the way that dealing with Covid has generated considerable solidarity within many communities. A sense of a shared problem and sharing of sacrifice is widespread. Opposition to lockdowns might perhaps seen as rejecting this valuable social-emotional achievement. My reply is that the positive side of this psychological change need not be tied to the policies opposed here. Wanting to encourage and preserve a cooperative atmosphere does not entail the closure of schools and abuse of administrative power. Indeed, a more voluntarist, less coercive approach to the situation might push this sense of solidarity further.

This essay has been written in stages from December 2020. One correspondent said to me, after the first installment was posted online in January 2021, that we are probably now near the end of this crisis, and I should perhaps position the essay so that it bears more on future pandemics. My correspondent was in the UK, which was then in lockdown and only emerged fully from restrictions six months later. The problem has not receded so quickly. The likelihood of new strains appearing through ongoing viral evolution also remains, and we don't know what the next northern winter might bring. Still, I agree that part of the message is how we might do better next time. Both in the case of Covid itself and those future challenges, we need to be more responsive to the costs of lockdowns, especially given their limited benefits over the past year, and we need to be more cogniscent of the value of liberties in the realm of everyday behavior. We also need to react to crises with a stronger sense of our responsibility to young people, with a recognition of what makes life remain valuable for many older people, and an unwillingness to let fear call all the shots.

\section{References}

1. https://gbdeclaration.org.

2. https://coronavirus.jhu.edu. Accessed September 2021.

3. https://www.cdc.gov/mmwr/volumes/69/wr/mm6928e1.htm. Data through May 2020.

4. https://www.ons.gov.uk/peoplepopulationandcommunity/birthsdeathsandmarriages/deaths/adhocs/ 12376averageageofdeathmedianandmeanofpersonswhosedeathwasduetocovid19orinvolvedcovid1 9bysexdeathsregistereduptoweekending2october2020englandandwales. Data through October 2020.

5. https://www.health.gov.au/resources/publications/coronavirus-covid-19-at-a-glance-4-july-2021. Data through July 2021.

6. Woolf, S.H., D.A. Chapman, R.T. Sabo, and E.B. Zimmerman. 2021. Excess deaths from COVID19 and other causes in the US, March 1, 2020, to January 2, 2021. JAMA 325 (17): 1786-1789. https://doi.org/10.1001/jama.2021.5199.

7. O’Driscoll, M., G. Ribeiro Dos Santos, L. Wang, et al. 2021. Age-specific mortality and immunity patterns of SARS-CoV-2. Nature 590: 140-145. https://doi.org/10.1038/s41586-020-2918-0.

8. https://www.nytimes.com/2021/01/02/opinion/sunday/2020-worst-year-famine.html. 
9. Akçay, E. 2021. “Against 'Covid Heterodoxy:' Open review of Godfrey-Smith, 2021.” https://erola kcay.files.wordpress.com/2021/08/godfreysmithreview-1.pdf.

10. Godfrey-Smith, P. 2021. Reply to Akçay. https://petergodfreysmith.com/wp-content/uploads/2021/ 08/Reply-to-Akcay-PGS-2021.pdf.

11. https://www.ama-assn.org/system/files/2021-02/covid-19-vaccine-guide-english.pdf. Accessed September 2021.

12. https://commonslibrary.parliament.uk/research-briefings/cbp-9068/.

13. Birch, J. 2020. Science and policy in extremis: the UK's initial response to COVID-19. European Journal for Philosophy of Science 11: 90. https://doi.org/10.1007/s13194-021-00407-z.

14. Lipsitch, M. 2020. Good science is good science. Boston Review, 12 May 2020. https://bostonrevi ew.net/science-nature/marc-lipsitch-good-science-good-science.

15. Trichopoulos, D., and H.O. Adami. 2001. Cellular telephones and brain tumors. New England Journal of Medicine 344 (2): 133-134. https://doi.org/10.1056/NEJM200101113440209 (PMID: 11150365).

16. https://www.nytimes.com/2020/12/24/us/remote-learning-student-income.html.

17. De Larochelambert, Q., M. Andy, A. Juliana, E. Le Bourg, and J. Toussaint. 2020. Covid-19 mortality: A matter of vulnerability among nations facing limited margins of adaptation. Frontiers in Public Health 8: 604339. https://doi.org/10.3389/fpubh.2020.604339.

18. Chaudhrya, R., G. Dranitsarisb, T. Mubashirc, J. Bartoszkoa, and S. Riazia. 2020. A country level analysis measuring the impact of government actions, country preparedness and socioeconomic factors on COVID-19 mortality and related health outcomes. EClinicalMedicine 25 (2020): 100464. https://doi.org/10.1016/j.eclinm.2020.100464.

19. Leffler, C.T., E. Ing, J.D. Lykins, M. Hogan, C.A. McKeown, and A. Grzybowski. 2020. Association of country-wide Coronavirus mortality with demographics, testing, lockdowns, and public wearing of masks. American Journal of Tropical Medicine and Hygiene 103 (6): 2400-2411. https://doi.org/ 10.4269/ajtmh.20-1015.

20. Allen, D.W. 2021. Covid lockdown cost/benefits: A critical assessment of the literature. https:// www.sfu.ca/ allen/LockdownReport.pdf.

21. https://twitter.com/martinmckee/status/1411068941481435138.

22. https://www.statista.com/statistics/525353/sweden-number-of-deaths/. Accessed September 2021.

23. https://www.statista.com/statistics/1109011/coronavirus-covid19-death-rates-us-by-state/. Accessed September 2021.

24. https://ourworldindata.org/coronavirus/country/sweden. Accessed October 2021.

25. Grafton, R.Q., J. Parslow, T. Kompas, K. Glass, and E. Banks. 2020. Health and economic effects of COVID-19 control in Australia: Modelling and quantifying the payoffs of 'hard' versus 'soft' lockdown. https://www.medrxiv.org/content/10.1101/2020.08.31.20185587v1.full.pdf.

26. Kompas, T., R.Q. Grafton, T.N. Che, L. Chu, and J. Camac. 2021. Health and economic costs of early and delayed suppression and the unmitigated spread of COVID-19: The case of Australia. PLoS ONE 16 (6): e0252400. https://doi.org/10.1371/journal.pone.0252400.

27. Miles, D., M. Stedman, and A. Heald. 2020. Living with COVID-19: Balancing costs against benefits in the face of the virus. National Institute Economic Review 253: R60-R76. https://doi.org/10. 1017/nie.2020.30.

28. https://www.bcg.com/en-us/publications/2020/why-its-not-too-late-to-contain-the-virus.

29. https://ourworldindata.org/covid-health-economy.

30. https://www.reuters.com/world/asia-pacific/south-korea-raise-covid-19-curbs-highe st-level-seoul-says-pm-2021-07-08/.

31. https://www.theguardian.com/business/2020/oct/07/covid-19-crisis-boosts-the-fortunes-of-worldsbillionaires.

32. https://www.nytimes.com/2021/01/01/upshot/why-markets-boomed-2020.html?action=click\&module $=$ Top $\% 20$ Stories\&pgtype $=$ Homepage.

33. https://newrepublic.com/article/153870/inequality-death-america-life-expectancy-gap.

34. https://www.bbc.com/news/world-australia-54007824.

35. https://www.bbc.com/news/explainers-52106843.

36. https://www.bbc.com/news/uk-england-derbyshire-55594244.

37. https://www.theguardian.com/australia-news/2020/aug/26/victoria-police-issue-almost-20000-finesfor-covid-19-breaches-during-pandemic.

38. https://www.nytimes.com/2020/12/17/world/australia/melbourne-lockdown-covid-human-rights. html? smid=tw-share. 
39. Winsberg, E., J. Brennan, and C.W. Surprenant. 2020. How government leaders violated their epistemic duties during the SARS-CoV-2 crisis. Kennedy Institute of Ethics Journal 30 (3-4). https:// kiej.georgetown.edu/leaders-violated-epistemic-duties-special-issue/.

40. https://www.thetimes.co.uk/article/people-don-t-agree-with-lockdown-and-try-to-undermine-thescientists-gnms $7 \mathrm{mp} 98$.

41. https://www.smh.com.au/national/victoria/how-we-beat-covid-part-one-the-way-in-20201210p56mdr.html.

42. https://www.standard.co.uk/news/politics/lockdown-boris-johnson-yougov-poll-b680047.html.

43. https://www.theguardian.com/law/2021/jan/17/jonathan-sumption-cancer-patient-life-less-valua ble-others.

44. https://www.theguardian.com/world/2021/jun/02/a-sacrificed-generation-psychological-scars-ofcovid-on-young-may-have-lasting-impact.

45. https://www.smh.com.au/national/pandemic-exposes-global-fault-lines-and-how-australia-roseabove-them-20201211-p56mn4.html.

46. https://www.brookings.edu/research/how-misinformation-is-distorting-covid-policies-and-behav iors/?preview_id=1316949.

47. https://www.independent.co.uk/tv/editors-picks/social-distancing-ignored-in-mass-snowball-fightin-leeds-park-XS9KoD2X. https://westyorkshire.police.uk/news-appeals/two-men-given-ps10000coronavirus-fines-over-leeds-snowball-fight.

48. https://www.smh.com.au/national/nsw/no-open-and-shut-case-nsw-playing-the-long-game-againstthe-virus-20210101-p56r75.html.

49. https://www.nytimes.com/2021/05/29/travel/a-farewell-from-at-home.html.

50. https://www.nytimes.com/2021/01/18/briefing/donald-trump-pardon-phil-spector-coronavirusdeaths.html.

51. https://www.nytimes.com/2021/03/02/opinion/covid-vaccine-coronavirus.html.

Publisher's Note Springer Nature remains neutral with regard to jurisdictional claims in published maps and institutional affiliations. 